\title{
Evolution of Rural Production Space System and its Sustainable Development Capacity with Information Entropy in China
}

\author{
Cheng Wang ${ }^{1 *}$, Qin $\mathrm{Li}^{1}$, Yanzhou He${ }^{2}$, Zhuoqi Long ${ }^{3}$ \\ ${ }^{1}$ School of Geographical Sciences, Southwest University, Chongqing, China \\ ${ }^{2}$ China Academy of Urban Planning and Design Western Branch, Chongqing, China \\ ${ }^{3}$ The Second Surveying and Mapping Institute of Hunan Province, Changsha, China
}

Received: 8 August 2020

Accepted: 20 December 2020

\begin{abstract}
The sustainable development of rural production space system (RPSS) is the key to rural revitalization in China. Based on the flow-driven model for the evolution of RPSS and the entropy change model of RPSS, evolution law and sustainable development capacity of RPSS in China from 2008 to 2017 are analysed using the entropy weight method. The following main conclusions are drawn: (1) From 2008 to 2017, total entropy of RPSS in China showed a downward trend, the score of system sustainable development capacity showed an upward trend, and the system developed in an orderly, sustainable manner. Sustainable development strategies of RPSS are proposed through the analysis of specific indicators. (2) The information entropy model is a feasible, effective mathematical model to explain the flow-driven mechanism for the evolution of RPSS. (3) The index system based on information entropy model provides a perspective for the study of rural sustainable development. Research results provide theoretical guidance for optimising RPSS and rural revitalization.
\end{abstract}

Keywords: rural production space system, evolution; sustainable development, information entropy

\section{Introduction}

The compression of rural space is increasingly worsening with the rapid development of urbanisation and industrialisation worldwide [1-4]. China is currently at a stage of accelerated urbanisation and industrialisation when the contradiction between construction land expansion and rural production space compression is particularly prominent [5]. According to

*e-mail: wchorange@126.com the World Bank Data, urbanisation rate rose rapidly from $17.9 \%$ in 1978 to $60.308 \%$ in 2019 , whilst the proportion of China's rural population to total population decreased from $82.1 \%$ to $39.692 \%[6,7]$. Since the $21^{\text {st }}$ century, China's farmland has rapidly turned to construction land, of which $84 \%$ of the lost farmland turned to construction land from 2010 to 2015 [8, 9]. Conversely, rural residential area increased by an average of $0.1 \%$ annually from 2000 to 2007 [10]. The loss of rural population and farmland as well as the increase of rural residential land has combined to cause rural production space compression [11]. In addition, the production mode and management practices in rural China 
are undergoing profound changes, such as traditional field crops to cash crops and single agricultural crops to the development of high-value-added industries. From 2000 to 2018 , the proportion of traditional crop planting area to the total planting area of crops increased by $1.66 \%$, whereas that of cash crops increased by $6.7 \%$, which is about four times that of traditional crops [12]. Thus, accelerated urbanisation and subsequent increase of human activities are triggering tremendous land use transitions in China and bringing about direct socio-economic and environmental effects on rural sustainability, thus resulting in farmland loss and land degradation, affecting the ability of ecosystems to serve human needs, influencing agricultural production and causing socio-economic and spatial restructuring of rural area [13-18]. Therefore, the sustainable development of rural areas is facing great challenges in China. A series of polices on rural development has been issued by the Chinese government to overcome these challenges [19]. Examples include proposing the policy of building a new countryside in 2005; drawing a 120 million hectare farmland-red-line and practicing the strictest farmland protection in 2006; focusing on the issues of agriculture, rural areas and farmers in the annual Central Document No. 1 since 2004; proposing the Rural Revitalisation Strategy in 2017 and issuing the Strategic Plan for Rural Revitalisation (2018-2022) in 2018. The essence of all these policies is to ensure the sustainability of rural development. Moreover, industry can enhance the internal strength of a rural area, which is the basis of sustainable rural development [20]. Industrial revitalisation is the important foundation of Rural Revitalisation and the premise of solving all rural problems. Therefore, the State Council issued the Guiding Opinions on Promoting the Revitalisation of Rural Industries in 2019, and the National Rural Industry Development Plan (2020-2025) was issued in the next year. China has attached great importance to the revitalisation of rural industries to a new height. Rural production space system (RPSS) is the spatial carrier of the rural industry [21]. Thus, promoting the sustainable development of RPSS would be the key to revitalising rural industries and rural areas.

RPSS was proposed by Chinese scholar Professor Wang in 2017 and is an open system with typical characteristics of dissipative structure. As an important part of the territory system of human-land relationship, RPSS can fully reflect the process of the multiple rural subjects acting on the land. At present, the connotation, elements, structure, function, operation mechanism and evolution mechanism of RPSS have been deconstructed to some extent [21-28], and the following core views have been obtained: (1) RPSS is a complex socio-economic relationship formed by multiple rural subjects carrying out various social production activities in the rural production space. It is a dynamic structure and a spatial aggregate with certain structural form and functional combination mechanism. (2) RPSS is a typical dissipative structure characterised by comprehensiveness and openness, nonlinearity and uncertainty, far from equilibrium and fluctuation. (3) Elements of RPSS are divided into basic elements (resource environment and infrastructure), core elements (diversified operation subjects), driving elements (information, capital, technology and market) and management elements (institutions and policies). The various elements are connected, interacted with each other and promote the operation of the system through support and restraint mechanisms, competition and cooperation mechanisms, and regulation and feedback mechanisms. (4) The evolution of RPSS is the result of the material, energy and information exchange within and between RPSS and the external system. The advantages and disadvantages of this result guarantee the sustainable development of the system. The academic circle has a relatively unified theoretical cognition of RPSS and its evolution, but there is still a lack of relevant empirical research. How to analyse the evolution law and sustainable development capacity of RPSS, and optimize RPSS have important practical value to establish the sustainable endogenous mechanism, enhance the internal strength of rural development and implement the Rural Revitalisation Strategy. It will help China's rural area to actively cope with the challenges of diversification of subjects and environmental degradation. At the same time, it will also provide some theoretical guidance for the national and local governments to formulate policies on promoting Rural Revitalisation.

Therefore, this work aims to achieve the following goals: (1) prove that the mathematical model of information entropy is feasible and effective for explaining the evolution mechanism of RPSS, and suitable for mining the evolution law of RPSS at the national scale; (2) prove the applicability of the index system based on the information entropy model in evaluating the sustainable development capacity of RPSS; (3) analyse the evolution law of RPSS and its sustainable development capacity from 2008 to 2017 and examine the corresponding countermeasures.

\section{Material and Methods}

\section{Theoretical Source and Mathematical Model}

\section{Flow-Driven Model for the Evolution of RPSS}

Stimulated by a series of policies, changes will occur in the material, energy and information input into RPSS. These changes will affect the interaction mode of internal elements such as multiple subjects (people), objects (land) and environment. In the interaction (i.e. self-organisation), the system absorbs, reorganises and renews to form new elements, structures and functions, and outputs new materials, energy and information through a certain interface. Over time, the interface will form a new RPSS. Fig. 1 is the evolution mechanism 


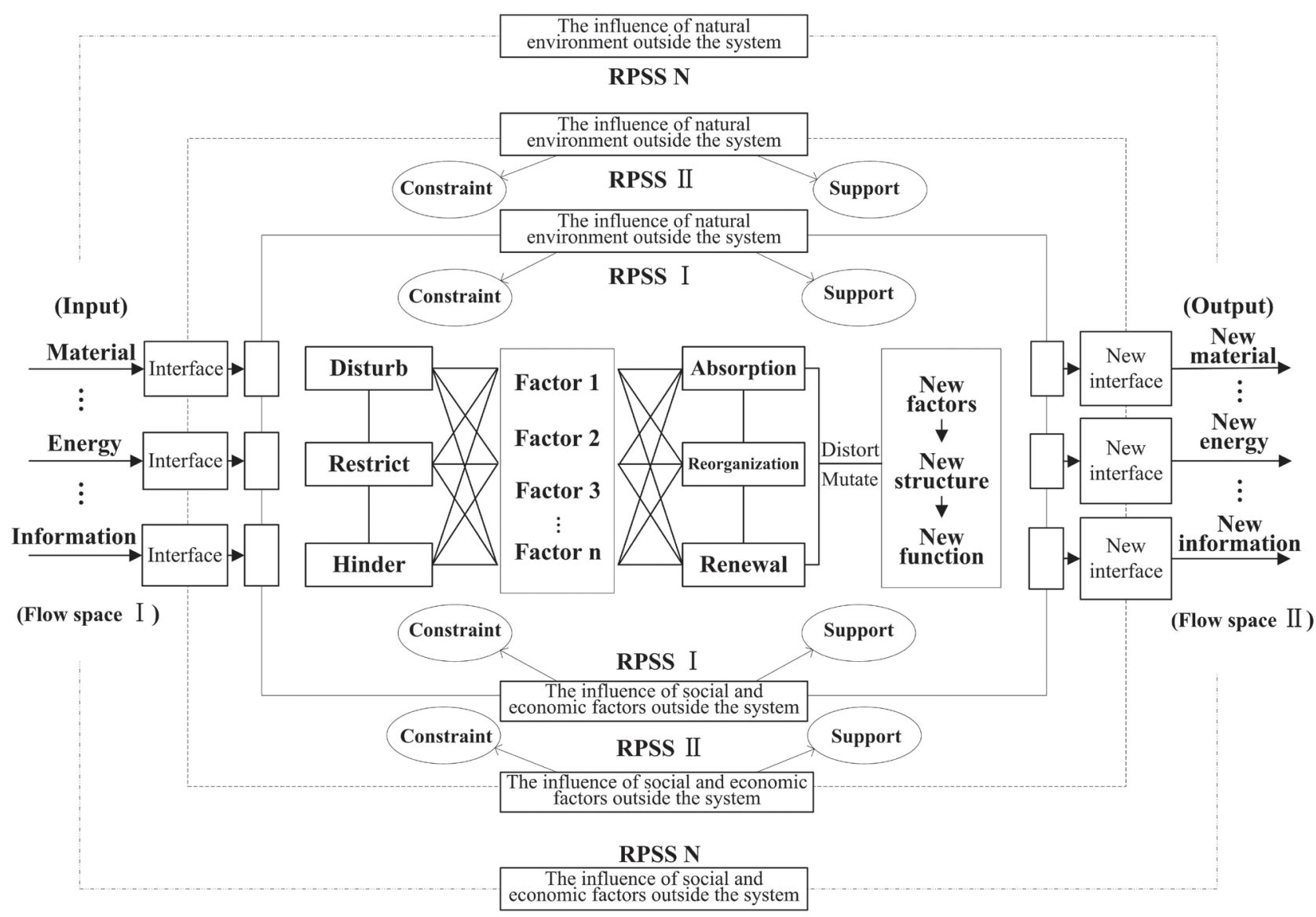

Fig. 1. Flow-driven model for the evolution of RPSS [28]. (The figure is derived from the research results of our team and has been modified).

of RPSS. Interactions between elements within the system and those outside the system are maintained in the form of 'flows' (material, energy, information, economic, population and society). Amongst them, the interaction within the system is extremely complex, whereas the material, energy and information of the input and output system can be quantified by indicators. This finding is consistent with black box theory. The black box method explores the internal structure and mechanism of the black box by observing the changing relationship between the information input from outside and the information output from the black box. It does not need to open the system itself to study the internal structure and mechanism of the system. Therefore, regarding RPSS as a 'black box', a flow-driven model for the evolution of RPSS is constructed by describing the evolution path of the system externally (Fig. 1).

Generally, the evolution of RPSS is supported and restricted by specific natural environment and social economy, and its process can be divided into three levels. Firstly, when the material, energy and information input through a certain interface from outside break through the threshold, RPSS will be disturbed, restricted and hindered. In self-organisation operation, the system will change the interaction mode of factors through absorption, reorganisation and renewal, and form new elements, structures and functions. Secondly, the system outputs new material, energy and information through a new interface, completing the transition from flow space I to II. Thirdly, a new RPSS is gradually formed inside the new interface, and the system changes and runs in a new direction with a new state, that is, RPSS I evolves to II, or even to the higher level of RPSS N. The flow-driven mechanism of the evolution of RPSS provides a theoretical source for the selection of its mathematical model.

\section{Model of Information Entropy of RPSS}

Entropy is a concept of thermodynamics and a physical quantity that characterises the state of the system. In 1948, Shannon proposed information entropy theory, providing it a new meaning [29]. As a measure of information content, entropy can reflect the disorder degree and quantitatively judge the evolution direction of the system [30, 31]. The higher the entropy is, the more chaotic the operation of the system. Later, Belgian chemist and physicist Professor Ilya Prigogine established dissipative structure theory in the late 1960s [32]. Prigogine pointed out that the non-linear open system far from the equilibrium state continuously exchanges material, energy and information with 
the outside world. When the change of a parameter within the system reaches a certain threshold, selforganisation occurs, and a new stable and orderly system structure, i.e. dissipative structure is formed. An unbalanced system has many changing factors, which are interrelated and restricted by one another and determine the possible state and evolution direction of the system [33]. In addition, Prigogine proposed the total entropy change formula (Eq. 1) according to the second law of thermodynamics. Total entropy change of the system with a dissipative structure is composed of entropy production and entropy flux.

$$
d S=d{ }_{l} S+d e_{e}
$$

...where $d S$ denotes the total entropy change; $d S$ denotes the entropy production caused by the irreversible process inside the system, and $d_{i} S \geq 0 ; d_{e} S$ denotes the entropy flux caused by the exchange of material, energy and information between the system and the outside world, and its value can be positive, negative or zero.

- If $d S<0$, then $\left|d_{e} S\right|>d_{i} S$, and the evolution of the system is in a rapid growth stage.

- If $d S=0$, then $\left|d_{e} S\right|=d_{i} S$, and the evolution of the system is in a stable stage.

- If $d S>0$, then $|d S|<d S$, and the evolution of the system is in a declining stage.

RPSS has typical dissipative structure features, which can be represented by the total entropy change formula (Eq. 1). Therefore, information entropy theory could reveal evolution law of RPSS. Specifically, the interior of RPSS is an irreversible process.
The deterioration of environment quality and the construction of ecological environment in the system lead to increased entropy, and entropy production occurs. Simultaneously, the material circulation, energy flow and information conversion between the system and the external environment lead to the exchange of entropy, and entropy flux occurs. Under the influence of external disturbance and internal fluctuation, total entropy change occurs, causing the succession and changes of the system. Continuously introducing negative entropy flux from the external environment to offset the influence of entropy production inside the system is the key of the evolution of the system towards order or even higher order. This mathematical model is an expression of the flow-driven mechanism. Entropy flux represents the input-output pattern of the system, and entropy production represents the internal absorption, reorganisation and renewal of the system after it is disturbed, restricted and hindered. This process could be characterised by the entropy change mode of RPSS (Fig. 2).

The information entropy has been widely used in research areas of simulation of soil particle size distribution, design of urban water quality monitoring network, analysis of urban landscape pattern change, quality growth of urban economic system, exploration and prediction of spatial-temporal evolution law of land use structure, evolution analysis of urban population density [34-40]. At present, information entropy has been extended to the evaluation of various social, economic and ecological systems. Among them, the results of research on urban ecosystems, marine

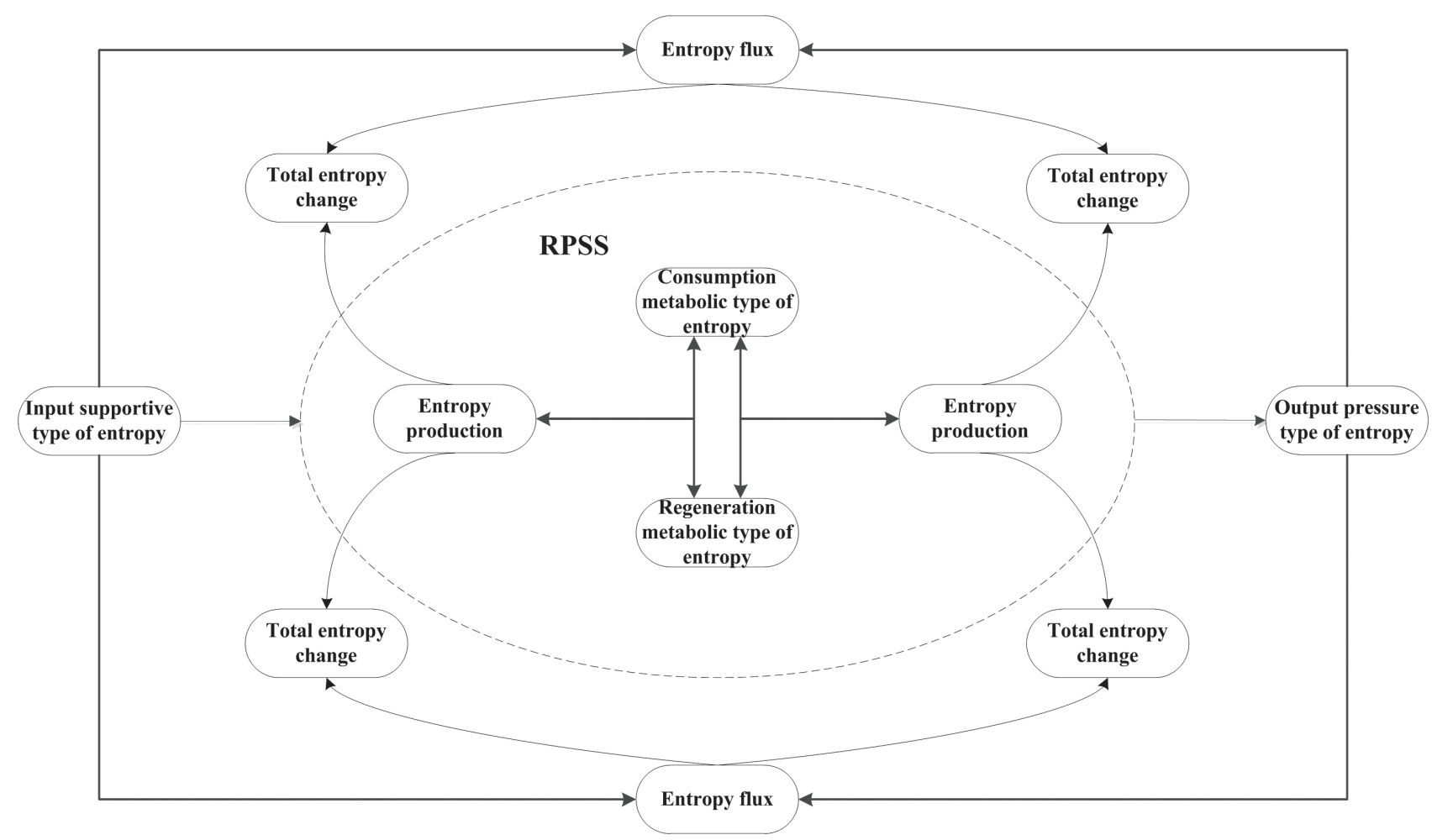

Fig. 2. Entropy change mode of RPSS [22]. (The figure is derived from the research results of our team and has been modified). 
Table 1. Symbols, formulas and characterisations of entropy flux, entropy production and total entropy change of RPSS.

\begin{tabular}{|c|c|c|}
\hline Items & Symbols and formulas & Characterisations \\
\hline Input supportive type of entropy & $\Delta_{e} S_{1}$ & Disorder degree of RPSS \\
\hline Output pressure type of entropy & $\Delta_{e} S_{2}$ & Disorder degree of RPSS \\
\hline Consumption metabolic type of entropy & $\Delta_{i} S_{1}$ & Disorder degree of RPSS \\
\hline Regeneration metabolic type of entropy & $\Delta_{i} S_{2}$ & Disorder degree of RPSS \\
\hline Entropy flux & $\Delta_{e} S_{2}-\Delta_{e} S_{1}$ & Coordination of RPSS \\
\hline Entropy production & $\Delta_{i} S_{2}-\Delta_{i} S_{1}$ & Vitality of RPSS \\
\hline Total entropy change & $\left(\Delta_{e} S_{2}-\Delta_{e} S_{1}\right)+\left(\Delta_{i} S_{2}-\Delta_{i} S_{1}\right)$ & Order and health level of RPSS \\
\hline
\end{tabular}

ecosystems, etc. have shown that information entropy can reflect the evolution of the system, and can also identify the sustainable development status and health level of the system [31, 41]. Thus, this study draws on relevant research results of urban ecosystem evolution and RPSS evolution [22, 42], and refines information entropy of RPSS into the following types of entropy: input supportive, output pressure, consumption metabolic and regeneration metabolic. The information entropy model' of RPSS (Eq. 2) is constructed, and its symbol and formulas are shown in Table 1.

$$
d S=d_{i} S+d_{e} S=\left(\Delta_{i} S_{2}-\Delta_{i} S_{1}\right)+\left(\Delta_{e} S_{2}-\Delta_{e} S_{1}\right)
$$

\section{Establishment of an Index System}

According to the flow-driven model and the information entropy model, and considering the national macro scale and following principles of systematisation, representativeness and operability, 36 indicators from four aspects are selected to establish the index system for the evolution and sustainable development capacity evaluation of RPSS in China (Table 2).

Table 2. Index system of RPSS evolution in China.

\begin{tabular}{|c|c|c|c|}
\hline Indicator types & Indicators & Units & Weights \\
\hline \multirow{10}{*}{$\begin{array}{l}\text { Input supportive } \\
\text { type of entropy } \\
\text { (A) }\end{array}$} & Gross output of grain $\left(A_{1}\right)$ & $\times 10^{4} \mathrm{t}$ & 0.026 \\
\hline & Gross output of vegetables $\left(\mathrm{A}_{2}\right)$ & $\times 10^{4} \mathrm{t}$ & 0.027 \\
\hline & Gross output of fruits $\left(\mathrm{A}_{3}\right)$ & $\times 10^{4} \mathrm{t}$ & 0.021 \\
\hline & Gross output of aquatic products $\left(\mathrm{A}_{4}\right)$ & $\times 10^{4} \mathrm{t}$ & 0.021 \\
\hline & Gross output of meat $\left(\mathrm{A}_{5}\right)$ & $\times 10^{4} \mathrm{t}$ & 0.017 \\
\hline & Gross output value of agriculture, forestry animal husbandry and fishery $\left(\mathrm{A}_{6}\right)$ & $\times 10^{8} \mathrm{RMB}$ & 0.026 \\
\hline & Total output value of township enterprises $\left(\mathrm{A}_{7}\right)$ & $\times 10^{8} \mathrm{RMB}$ & 0.025 \\
\hline & Comprehensive income of rural tourism $\left(\mathrm{A}_{8}\right)$ & $\times 10^{8} \mathrm{RMB}$ & 0.038 \\
\hline & Per capita net income of rural residents $\left(\mathrm{A}_{9}\right)$ & RMB & 0.030 \\
\hline & Total value of import and export of agricultural products $\left(\mathrm{A}_{10}\right)$ & $\times 10^{8}$ USD & 0.022 \\
\hline \multirow{10}{*}{$\begin{array}{l}\text { Output pressure } \\
\text { type of entropy } \\
\text { (B) }\end{array}$} & Number of employed persons by rural areas $\left(B_{1}\right)$ & $\times 10^{4}$ person & 0.022 \\
\hline & Rural tourist number $\left(\mathrm{B}_{2}\right)$ & $\times 10^{8}$ person & 0.017 \\
\hline & Expenditure for agriculture, forest and water conservation $\left(\mathrm{B}_{3}\right)$ & $\times 10^{8}$ USD & 0.030 \\
\hline & Agricultural water consumption $\left(\mathrm{B}_{4}\right)$ & $\times 10^{8} \mathrm{~m}^{3}$ & 0.025 \\
\hline & Agricultural fertiliser consumption $\left(\mathrm{B}_{5}\right)$ & $\times 10^{4} \mathrm{t}$ & 0.043 \\
\hline & Amount of agricultural film use $\left(\mathrm{B}_{6}\right)$ & $\times 10^{4} \mathrm{t}$ & 0.046 \\
\hline & Amount of pesticide use $\left(B_{7}\right)$ & $\times 10^{4} \mathrm{t}$ & 0.048 \\
\hline & Power consumption of rural production $\left(\mathrm{B}_{8}\right)$ & $\times 10^{8} \mathrm{kWh}$ & 0.034 \\
\hline & Final energy consumption of primary industry $\left(\mathrm{B}_{9}\right)$ & $\times 10^{4} \mathrm{t}$ of SCE & 0.019 \\
\hline & Operating expenses of rural households $\left(\mathrm{B}_{10}\right)$ & $\mathrm{RMB} /$ person & 0.036 \\
\hline
\end{tabular}


Table 2. Continued.

\begin{tabular}{|c|c|c|c|}
\hline \multirow{8}{*}{$\begin{array}{l}\text { Consumption } \\
\text { metabolic type of } \\
\text { entropy }(\mathrm{C})\end{array}$} & Quantity of fertiliser pollution $\left(\mathrm{C}_{1}\right)$ & $\times 10^{4} \mathrm{t}$ & 0.041 \\
\hline & Quantity of crop straw pollution $\left(\mathrm{C}_{2}\right)$ & $\times 10^{4} \mathrm{t}$ & 0.028 \\
\hline & Quantity of livestock and poultry breeding pollution $\left(\mathrm{C}_{3}\right)$ & $\times 10^{4} \mathrm{t}$ & 0.045 \\
\hline & Agricultural source chemical oxygen demand $\left(\mathrm{C}_{4}\right)$ & $\times 10^{4} \mathrm{t}$ & 0.022 \\
\hline & Agricultural source amino-nitrogen emission $\left(\mathrm{C}_{5}\right)$ & $\times 10^{4} \mathrm{t}$ & 0.029 \\
\hline & Quantity of township enterprise wastewater effluent $\left(\mathrm{C}_{6}\right)$ & $\times 10^{4} \mathrm{t}$ & 0.029 \\
\hline & Pollutant quantity in flue gas of township enterprise $\left(\mathrm{C}_{7}\right)$ & $\times 10^{4} \mathrm{t}$ & 0.023 \\
\hline & Discharge solid waste pollution of township enterprises $\left(\mathrm{C}_{8}\right)$ & $\times 10^{4} \mathrm{t}$ & 0.024 \\
\hline \multirow{8}{*}{$\begin{array}{l}\text { Regeneration } \\
\text { metabolic type of } \\
\text { entropy (D) }\end{array}$} & Forest coverage rate $\left(D_{1}\right)$ & $\%$ & 0.012 \\
\hline & Rate of farmland returning to woodland $\left(\mathrm{D}_{2}\right)$ & $\%$ & 0.039 \\
\hline & Areas with flood prevention measures $\left(\mathrm{D}_{3}\right)$ & $\times 10^{4} \mathrm{hm}^{2}$ & 0.039 \\
\hline & Rural sanitary latrine penetration $\left(\mathrm{D}_{4}\right)$ & $\%$ & 0.019 \\
\hline & Water-saving irrigated area $\left(D_{5}\right)$ & $\times 10^{4} \mathrm{hm}^{2}$ & 0.022 \\
\hline & Ratio of rural environmental protection investment $\left(D_{6}\right)$ & $\%$ & 0.013 \\
\hline & Methane production from agricultural waste disposal project $\left(D_{7}\right)$ & $\times 10^{4} \mathrm{~m}^{3}$ & 0.020 \\
\hline & Annual output of straw high-quality energy utilisation $\left(\mathrm{D}_{8}\right)$ & $\mathrm{t}$ & 0.022 \\
\hline
\end{tabular}

Indicators of input supportive type of entropy (A1-A10) mainly reflect the productivity of the natural resources and multiple subjects in RPSS, which can show the supporting role of RPSS.

Indicators of output pressure type of entropy (B1-B10) mainly reflect the ability of multiple rural subjects to utilise or release material energy in production and operation, which can show the pressures undertaken by RPSS.

Indicators of consumption metabolic type of entropy (C1-C8) mainly reflect the negative influence on the environment caused by waste and pollutants discharged in rural production, and can show the entropy increase of RPSS.

Indicators of regeneration metabolic type of entropy (D1-D8) mainly reflect human's environmental protection and management level of various pollutants and wastes, which can show the reductive metabolic capacity of RPSS.

\section{Data Acquisition and Handling System}

\section{Data Collection}

This study takes $2008-2017$ as the research period and collects relevant data to ensure the availability and timeliness of data. The data mainly come from authoritative statistics such as China Statistical Yearbook (2009-2018), China Rural Statistical Yearbook (200-2018), China Agricultural Yearbook (2009-2018), China Population and Employment Statistical Yearbook (2019), China Energy Statistical Yearbook (2009-2018), China Agricultural Products
Processing Industry Yearbook (2009-2018), China Environmental Statistics Yearbook (2009-2018), China Tourism Statistics Bulletin (2008-2017), and China Environmental Situation Bulletin (2008-2017). In addition, part of the data on agricultural pollutant emissions is calculation data, and the calculation formulas referring to the research of Liang and Qin are as follows [43]:

- Quantity of fertiliser pollution = Quantity of chemical fertiliser (purity) $\times$ pollution loss coefficient.

- Quantity of crop straw pollution $=$ Crop yields $\times$ Crop straw grain ratio $\times(1-$ Straw utilisation ratio $)$ $\times$ Pollution production coefficient $\times$ Pollution loss coefficient.

- Quantity of livestock and poultry breeding pollution $=$ Total breeding $\times$ Emission coefficient of livestock and poultry manure $\times(1-$ Pollutant treatment and utilisation rate in feces) $\times$ Pollution loss coefficient.

\section{Data Standardisation}

Data standardisation of this study includes two aspects, namely, evolution analysis and evaluation of sustainable development capacity of RPSS.

Evolution analysis does not require distinguishing between positive index and negative index, because the information entropy model has vectorised indicators. Thus, the Z-score standardisation method is adopted here to normalise the data according to Eq. (3).

$$
Z=\frac{x-u}{\sigma}
$$


...where $z$ denotes the standard value, $x$ denotes the original value, $u$ denotes the average value and $\sigma$ denotes the standard deviation of the indicators.

For the evaluation of sustainable development capacity, the model does not vectorise the indicators; thus positive and negative indicators need to be distinguished. The input supportive type of entropy and regeneration metabolic type of entropy are negative entropy indicators, and the increase of indicators will promote the evolution of RPSS to an orderly, healthy direction, which are positive indicators. By contrast, the output pressure type of entropy and consumption metabolic type of entropy are positive entropy indicators, and the increase of indicators will make RPSS evolve to disorder and weakness, which are negative indicators. Therefore, the range standardisation method is adopted here to normalise the data according to Eqs. (4) and (5).

When the indicator is positive,

$$
Z_{i j}=\frac{X_{i j}-\min X_{i j}}{\max X_{i j}-\min X_{i j}}
$$

When the indicator is negative,

$$
Z_{i j}=\frac{\max X_{i j}-X_{i j}}{\max X_{i j}-\min X_{i j}}
$$

...where $Z_{i j}$ denotes the standard value, and $X_{i j}$ denotes the original value of the $j$-th year of the $i$-th indicator.

\section{Evolution Analysis Model of RPSS}

According to information entropy theory, random variable (i.e. $X$ ) represents its state characteristics for an uncertain system. For the random variable, the value of $x$ is $X=\left\{x_{1}, x_{2}, x_{3}, \ldots x_{n}\right\}(n \geq 2)$, the probability (i.e. $P_{i}$ ) for each value is $P=\left\{p_{1}, p_{2}, p_{3}, \ldots, p_{n}\right\}\left(0 \leq p_{i} \leq 1,2, \ldots\right)$, $\sum_{i=1}^{n} P_{i}=1$ and the information entropy is:

$$
S=-\sum_{i=1}^{n} p_{i} \cdot \ln \left(p_{i}\right)
$$

...where $S$ denotes the information entropy of the uncertain system, and $p_{i}$ denotes the probability of the discrete random variable $X$.

Information entropy (i.e. $\Delta S$ ) of the system is expressed as follows to evaluate $\mathrm{n}$ indicators and $\mathrm{m}$ years of RPSS:

$$
\Delta S=-\frac{1}{\ln m} \sum_{i=1}^{n} \frac{q_{i j}}{q_{j}} \cdot \ln \frac{q_{i j}}{q_{j}}
$$

...where $\Delta S$ denotes input supportive type of entropy, output pressure type of entropy, consumption metabolic type of entropy and regeneration metabolic type of entropy; $q_{i j}$ denotes the standard value; and $q_{j}$ denotes the sum of the standard value of the indicators in the $j$ year, i.e. $q_{j}=\sum_{i=1}^{n} q_{i j}(i=1,2, \ldots, n ; j=1,2, \ldots, m)$.

\section{Evaluation Model of Sustainable Development Capacity of RPSS}

The entropy weight method is an objective weight method, which can overcome the randomness and conjecture of the subjective weight method, effectively solve the problem of information overlap amongst multiple index variables, and deeply reflect the utility value of indicators' information entropy value. Therefore, the entropy weight method is adopted to calculate index weight according to Eqs. 8 and 9. The weights are shown in Table 2 (i.e. $W_{j}$ ).

Firstly, the information entropy is calculated as follows:

$$
E_{i}=-\frac{1}{\ln n} \sum_{i=1}^{n} \frac{Z_{i j}}{\sum_{i=1}^{n} Z_{i j}} \ln \frac{Z_{i j}}{\sum_{i=1}^{n} Z_{i j}}
$$

...where $W_{i}$ denotes the information entropy of the $i$-th indicator, and $Z_{i j}$ denotes the standard value.

Secondly, index weight is calculated as follows:

$$
W_{i}=\frac{1-E_{i}}{k-\sum E_{i}}\left(0<W_{i} ; \sum_{i=1}^{m} W_{i}=1 ; i=1,2, \ldots, n\right)
$$

...where $W_{i}$ denotes the weight of the $i$-th indicator. The larger $E_{i}$ of an indicator is, the less information transferred, i.e. the smaller the $W_{i}$ of the indicator. Conversely, the smaller the $E_{i}$ of an indicator is, the greater the $W_{i}$ of the indicator.

Combining standard value and weight of indicators, the score of sustainable development capacity of RPSS in China from 2008 to 2017 is calculated using the weighted summation method according to Eq. (10):

$$
G=\sum_{i=1}^{n} W_{i} \cdot X_{i}
$$

...where $G$ denotes the score of sustainable development capacity, $W_{i}$ denotes weight of the $i$-th indicator and $X_{i}$ denotes standard value of the $i$-th indicator. The higher the score is, the better the sustainable development capacity. Conversely, the lower the score is, the worse the sustainable development capacity. 
Table 3. Entropy change of RPSS in China from 2008 to 2017.

\begin{tabular}{|c|c|c|c|c|c|c|c|c|c|c|}
\hline \multirow{2}{*}{ Items } & \multicolumn{9}{|c|}{ Year } \\
\cline { 2 - 10 } & 2008 & 2009 & 2010 & 2011 & 2012 & 2013 & 2014 & 2015 & 2016 & 2017 \\
\hline Support type input entropy & 0.417 & 0.415 & 0.418 & 0.424 & 0.428 & 0.434 & 0.438 & 0.44 & 0.446 & 0.454 \\
\hline Output pressure type of entropy & 0.426 & 0.426 & 0.427 & 0.432 & 0.438 & 0.439 & 0.437 & 0.435 & 0.432 & 0.428 \\
\hline Consumption metabolic type of entropy & 0.465 & 0.465 & 0.457 & 0.448 & 0.437 & 0.43 & 0.427 & 0.425 & 0.413 & 0.397 \\
\hline Regeneration metabolic type of entropy & 0.335 & 0.339 & 0.343 & 0.343 & 0.343 & 0.343 & 0.344 & 0.346 & 0.353 & 0.364 \\
\hline Entropy flux & 0.009 & 0.011 & 0.009 & 0.008 & 0.009 & 0.005 & -0.001 & -0.006 & -0.014 & -0.027 \\
\hline Entropy production & 0.129 & 0.126 & 0.114 & 0.106 & 0.093 & 0.087 & 0.083 & 0.079 & 0.06 & 0.032 \\
\hline Total entropy change & 0.138 & 0.137 & 0.123 & 0.113 & 0.103 & 0.092 & 0.081 & 0.073 & 0.046 & 0.006 \\
\hline
\end{tabular}

\section{Results and Discussion}

\section{Time Series Analysis of Entropy Change in the Evolution of RPSS}

Table 3 shows the entropy change results of the evolution of RPSS in China from 2008 to 2017 calculated according to Eq. (7). Generally, total entropy change decreases annually, with the range from 0.138 to 0.006 in 2008-2017 (Table 3), indicating that the system evolved in an orderly, healthy direction. The results are produced by the interaction of entropy flux and entropy production, as shown in Figs 3 and 4.

\section{Analysis of Entropy Flux}

Fig. 3 shows that entropy flux presented a fluctuating downward trend from 2008 to 2017, including the largest entropy flux in 2009 and the continuous decline after 2012, indicating that the carrying capacity and coordination of RPSS were enhanced. The supporting role continued to increase except for 2008-2009. Output pressure type of entropy showed a trend of small wave-like increase, but it was much smaller than the increase of input supportive type of entropy. Entropy flux decreased with the interaction of the two types of entropy.

In 2009, entropy flux reached the maximum (Fig. 3), and the capacity and coordination of RPSS were the worst. This finding could be explained by the socio-economic background of China's rural production development. China's agriculture was severely challenged by the international financial crisis (2008) and natural disasters such as drought and flood. The export of agricultural products and the grain output declined, causing the total import and export of agricultural products a decrease of US $\$ 7.17$ billion and the total grain output an increase of only 5.066 million tons over the previous year. Rural tourism was in the early stage of development, and the integrated development of primary, secondary and tertiary industries in rural areas was slow with the relatively low level of industrial development.
The comprehensive income of rural tourism, the total output value of agriculture, forestry, animal husbandry and fishery, and the per capita net income of rural residents were only 30 billion yuan, 189.05 billion yuan and 392.6 yuan higher than that of the previous year, respectively. These factors led to the lesser supporting role of RPSS. Moreover, the pressure of rural production on RPSS remained almost unchanged from 2008 to 2009. Although rural production still increased output by increasing resource consumption and using agricultural products, the pressure brought by the above behaviours was offset by the continuous decline of rural employment population and the decrease of rural household operating expenses. The smaller input supportive type of entropy and the unreduced output pressure type of entropy led to the largest entropy flux of RPSS in 2009.

Since 2012, the trend of entropy flux decline has been increasing (Fig. 3), and the carrying capacity and coordination of RPSS have been increasing substantially. In 2012, the Ministry of Agriculture and Rural Affairs of the People Republic of China first proposed the concept of 'urban modern agriculture', and the rural tourism industry has been booming. Since then, the state has strengthened vocational training for township enterprises in the western region, and the interregional agricultural products' processing industry of township enterprises has developed towards cooperation. Moreover, the establishment of highyield grain, oil and sugar and the demonstration of standardised large-scale breeding of livestock and poultry have achieved remarkable results. Therefore, compared with 2012, the annual growth of the comprehensive income of rural tourism, total output value of township enterprises, and total output of grain, vegetables, fruits and meat increased to 100 billion yuan, 64.852 billion yuan, 98.762 million tons, 15.1364 million tons, 6.308 million tons and 1.886 million tons, respectively. In 2014, the State Council issued 'Opinions on Guiding the Orderly Circulation of Rural Land Management Rights to Develop Agricultural Moderate Scale Operations', which further improved agricultural production efficiency and farmers' income, 


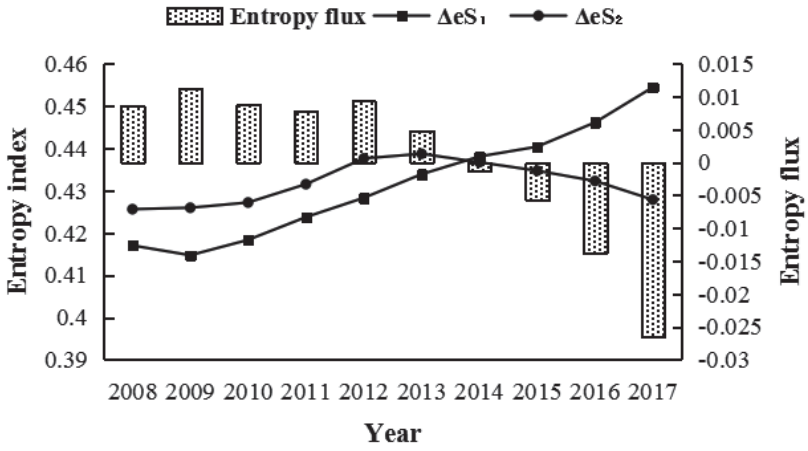

Fig. 3. Entropy flux of RPSS in China from 2008 to 2017.

and entropy flux began to be negative. These factors greatly enhanced the supporting role of RPSS. In 2012, the $18^{\text {th }}$ National Congress of the Communist Party of China proposed the concept of 'ecological civilisation construction', and the State Council issued the ' $12^{\text {th }}$ Five-Year Plan for Energy Conservation and Emission Reduction'. Rural areas across the country strictly controlled the use of agricultural fertilisers, agricultural films and pesticides, and the resource consumption of rural production activities such as agricultural water consumption and rural production electricity consumption, with their annual growth down to 41,200 tons, 29,000 tons, $-30,200$ tons, -2.72 billion cubic meters and 28.39 billion $\mathrm{kWh}$, respectively. This development prompted the pressure on RPSS to begin to ease. The greatly enhanced input supportive type of entropy and reduced output pressure type of entropy together contributed to a substantial decline in entropy flux from 2012 to 2017.

\section{Analysis of Entropy Production}

Entropy production showed a continuous downward trend from 2008 to 2017 (Fig. 4), indicating that the system's reduction and regeneration capacity became stronger, and its vitality gradually increased.

From 2008 to 2017, consumption metabolic type of entropy showed a declining trend (Fig. 4), and the negative effect of rural production activities on environment was controlled. The Ministry of Ecology Environment of the People's Republic of China successively issued the $12^{\text {th }}$ and $13^{\text {th }}$ FiveYear Plan for Comprehensive Rural Environmental Remediation. All regions focused on solving outstanding rural environmental problems, including agricultural non-point source pollution and township enterprise pollution. Governments at all levels actively implemented the policy of 'promoting treatment with awards', and comprehensively carried out special law enforcement inspection actions for straw burning. Moreover, the environmental effect assessment system was strictly implemented in the production of township enterprise. Township enterprises with large resource consumption and pollution were resolutely restricted

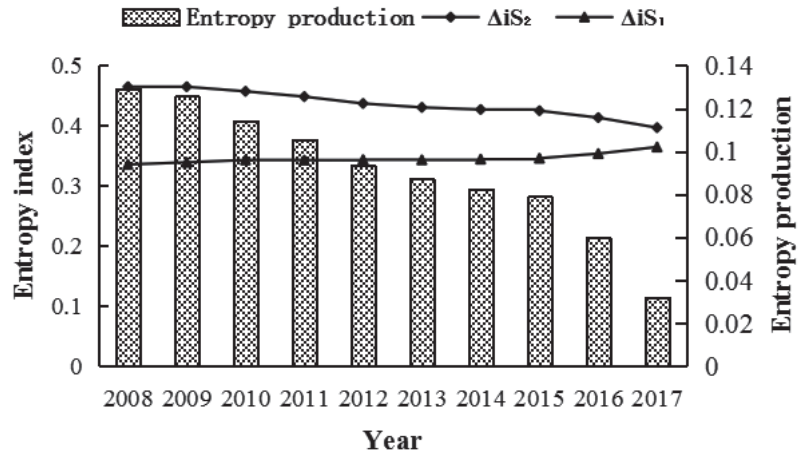

Fig. 4. Entropy production of RPSS in China from 2008 to 2017.

or even eliminated. Compared with 2008, agriculture source chemical oxygen demand emissions, agricultural source amino-nitrogen emission, crop straw pollution, township enterprise wastewater effluents and township enterprise discharge solid waste pollution decreased by $21.27 \%, 21.75 \%, 4.02 \%, 2.82 \%$ and $91.05 \%$, respectively, in 2017. Conversely, regeneration metabolic type of entropy showed a fluctuation and rise trend (Fig. 4), and the efforts of rural environmental pollution control were strengthened with remarkable results. From the $11^{\text {th }}$ to $13^{\text {th }}$ Five-Year Plans, China paid more attention to the construction of ecological civilisation. For example, natural forest protection project and returning farmland to woodland project were accelerated, and farmland water conservancy facilities were constructed in a more centralized, integrated manner to improve the ability of RPSS to resist natural disasters. Moreover, the government continuously increased investment in rural environmental protection to improve rural human settlements, in which the utilisation of agricultural waste resources achieved remarkable results. Therefore, forest coverage rate, rate of farmland returning to woodland, area with flood prevention measures, water saving irrigation area, ratio of rural environmental protection investment, rural sanitary latrine penetration, annual output of straw high-quality energy utilisation, and methane production from agricultural waste disposal project increased by $18.78 \%, 17.06 \%, 11.20 \%$, $40.44 \%, \quad 194.04 \%, \quad 36.85 \%, \quad 1147.4 \%$ and 397.54 , respectively, from 2008 to 2017 . The continuous decline of consumption metabolic type of entropy and the small increase of regeneration metabolic type of entropy resulted in the decrease of entropy production, and reductive regeneration capacity and vitality of RPSS became stronger.

\section{Analysis of Sustainable Development Capacity of RPSS}

The sustainable development score of RPSS in China showed a trend of decreasing first and then rising with 2015 as the turning point, with the score increasing by $16.35 \%$ from 2008 to 2017 (Fig. 5), and the level of sustainable development of the system 


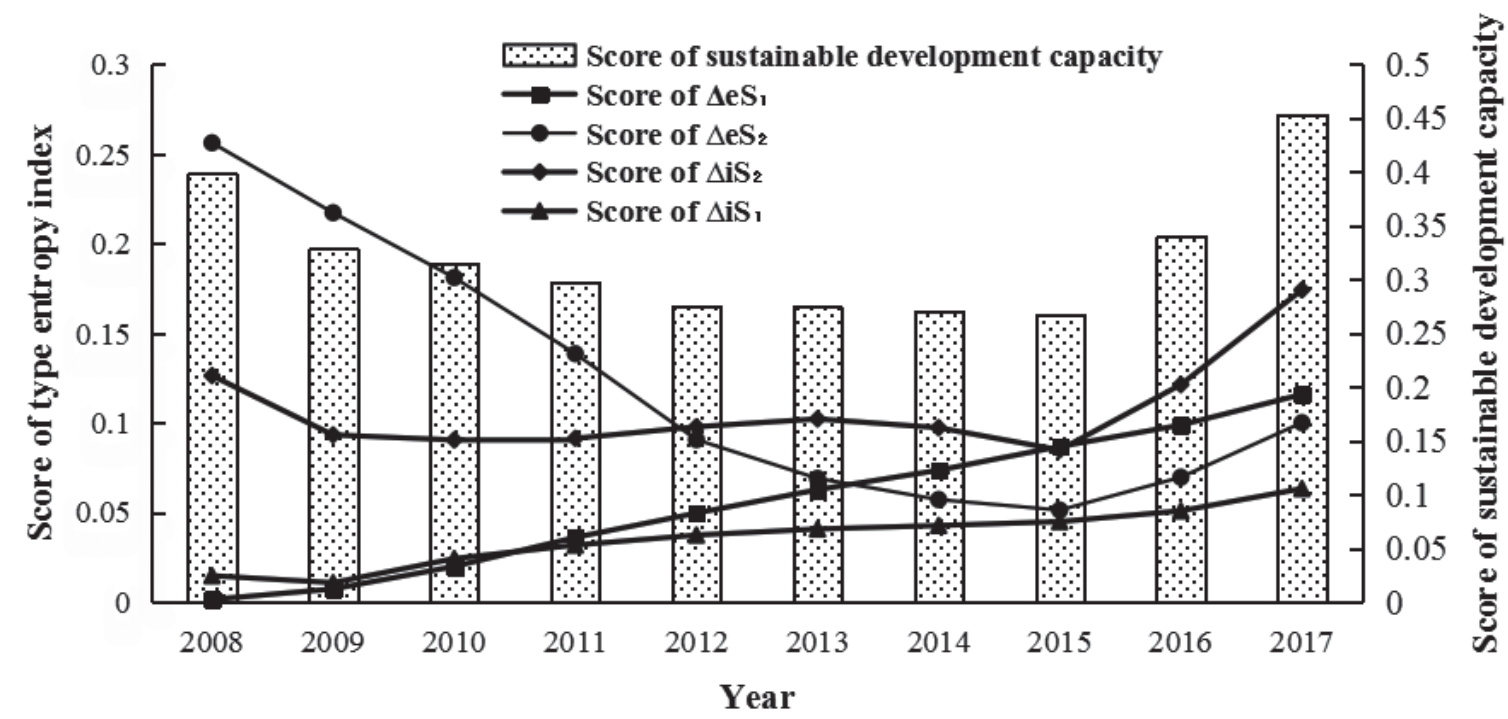

Fig. 5. Score of sustainable development capacity of RPSS in China from 2008 to 2017.

improved. The decrease of total score in the early stage was mainly affected by the decrease of output pressure type of entropy index score, whereas the increase in the later stage was mainly affected by the increase of input supportive type entropy and regeneration metabolic type of entropy index score.

Input supportive type of entropy index score showed a rising trend (Fig. 5), with an increase of $16.35 \%$, and the supporting role of the RPSS increased because the integration of rural primary, secondary and tertiary industries developed well, and all indicators were on the rise. The comprehensive income of rural tourism exhibited the most substantial growth, with an increase of $722.22 \%$, followed by the per capita net income of rural residents and the total output value of township enterprises, with increases of $182.16 \%$ and $161.44 \%$, respectively.

Output pressure type of entropy index score showed a downward trend and then an upward trend with 2015 as the inflection point (Fig. 5), totally down by $60.97 \%$, and the pressure on RPSS increased because the rural production still needed to consume a large amount of material resources and released much energy. Only rural employment population and amount of pesticide use decreased by $19.06 \%$ and $1.02 \%$, respectively, and the other indicators showed an upward trend. However, China has entered the $13^{\text {th }}$ Five-Year planning period since 2015, and Xi Jinping's 'Two Mountains Theory' has achieved numerous practical results. Agricultural water consumption, agricultural fertiliser consumption, amount of agricultural film and agricultural pesticide use have begun to decrease.

Consumption metabolic type of entropy index score showed a fluctuation and rise trend (Fig. 5), with an increase of $37.89 \%$, and the ecological environment of RPSS was improved because the pollutants discharged from rural production activities were effectively controlled, and quantity of township enterprise wastewater effluent, quantity of crop straw pollution, agricultural source chemical amino-nitrogen emission and agricultural source chemical oxygen demand decreased by $91.05 \%, 40.17 \%, 21.75 \%$ and $21.27 \%$, respectively.

Regeneration metabolic type of entropy index score showed an increasing trend (Fig. 5), up by $309.21 \%$, and the reductive metabolic function of RPSS was enhanced because rural environmental protection and pollution control were strengthened and achieved remarkable results. The score of various indicators showed a growing trend, amongst which annual output of straw high-quality energy utilisation and methane production from agricultural waste disposal project increased substantially, by $1147.4 \%$ and $397.54 \%$, respectively.

\section{Analysis on Sustainable Development Strategy of RPSS}

According to the index system constructed in this paper, the sustainable development capacity of RPSS can be improved from the four types of entropy: input supportive, output pressure, consumption metabolic and regeneration metabolic. Therefore, based on the analysis of the entropy weight and actual value of these four types of indicators in time series, we put forward targeted suggestions to improve the sustainable development capacity of RPSS in China.

\section{Strategy Analysis Based on Input Supportive Type of Entropy}

The entropy weights of the two indicators, namely, comprehensive income of rural tourism and per capita net income of rural residents, were relatively large (Table 2) amongst the input supportive type of entropy indicators, and their growth rates were relatively large at $722.22 \%$ and $182.16 \%$, respectively, indicating that they 
had the highest contribution to the enhancement of the supporting role of RPSS. In addition, the gross output of meat had the smallest entropy weight (Table 2) and the smallest increase range, which was the main direction to improve the productivity and carrying capacity of RPSS. The following suggestions are made: firstly, increase the social investment in leisure agriculture and rural tourism, and promote the development of leisure agriculture and rural tourism towards industrial scale, intensive operation and diversified connotation; secondly, strengthen the vocational skill training for farmers, encourage farmers to start their own businesses, strengthen the construction of agricultural infrastructure and raise the level and efficiency of farmers' income increase; thirdly, raise the scale level of animal husbandry, cultivate characteristic animal husbandry according to local conditions and improve the efficiency of animal husbandry.

\section{Strategy Analysis Based on Output Pressure Type of Entropy}

The entropy weights of the four indicators, namely, amount of pesticide use, amount of agricultural film use, agricultural fertiliser consumption and power consumption of rural production, were relatively large (Table 2) amongst the output pressure type of entropy indicators. Besides the amount of pesticide use, the three other indicators all showed an increasing trend, which was the breakthrough to relieve the pressure on RPSS. The following suggestions are made: firstly, strengthen the publicity and policy support, promote the new degradable film, liquid film and other new alternative products, and advance the collection and recovery technology of residual film to strengthen the residual film recycling; secondly, implement the chemical fertiliser reduction project, and encourage farmers and enterprises to accumulate and use organic fertiliser and plant green fertiliser; thirdly, increase investment to improve rural power infrastructure, implement rural power grid transformation and upgrade to reduce power waste.

\section{Strategy Analysis Based on Consumption Metabolic Type of Entropy}

Amongst the consumption metabolic type of entropy indicators, the two indicators of quantity of livestock and poultry breeding pollution and quantity of fertiliser pollution had greater entropy weights (Table 2), and their growth rates were large, with increases of $14.40 \%$ and $5.47 \%$, respectively, which was the key direction of pollution control. The following must be done: firstly, optimise the layout of the breeding areas, establish the system for the collection, storage, treatment and utilisation of livestock and poultry manure, develop circular agriculture combining planting and breeding, promote the use of harmless treatment and utilisation models such as the full collection of livestock and poultry manure and return to the field, and the ectopic fermentation bed; secondly, increase the special funds for pollution prevention, improve the standards for fertiliser pollution prevention, strictly regulate agricultural production and management behaviour, and promote the technology of soil testing formula precision fertilisation, mechanical deep fertilisation and water fertiliser integration.

\section{Strategy Analysis Based on Regeneration Metabolic Type of Entropy}

Amongst the regeneration metabolic type of entropy indicators, the four indicators of farmland returning to woodland rate, areas with flood prevention measures, water-saving irrigated area and annual output of straw high-quality energy utilisation had larger entropy weights (Table 2), and their growth rates were $17.06 \%$, $11.20 \%, 40.44 \%$ and $1147.4 \%$, respectively, which contributed substantially to improving the reduction regeneration function of RPSS. The entropy weights of the two indicators of forest coverage rate and ratio of rural environmental protection investment were relatively small (Table 2). The following recommendations are made. Firstly, improve the subsidy standard of the policy of returning farmland to woodland, and strengthen plantation maintenance management to improve the afforestation survival rate and preservation rate. Secondly, implement the action of small-scale water conservancy project transformation and upgrade, and strengthen the construction of agricultural irrigation and drainage project. Thirdly, establish an incentive mechanism for water-saving irrigation, promote water-saving irrigation technology models such as drip irrigation, infiltration irrigation and micro-sprinkler irrigation, and strengthen the water-saving irrigation technology training of grassroot technicians and farmers. Fourthly, strengthen the management of straw burning in the open air, accelerate the pilot of straw comprehensive utilisation and further promote straw energy utilisation technologies such as straw gasification and centralised gas supply technology, straw pyrolysis and carbonisation technology, and straw direct combustion power generation technology. Fifthly, intensify efforts to implement natural forest protection project, encourage the development of various forms of social afforestation such as the Alipay Ant Forest, and strictly prohibit deforestation. Sixthly, establish and improve the investment and financing mechanism for the diversified funds from the government, enterprises, society and farmers to participate in rural environmental protection and strengthen the supervision of the special funds.

\section{Discussion}

Based on the flow-driven model for the evolution and the information entropy model of RPSS, an appropriate index system at the national scale is 
constructed. This study analyses the evolution law of RPSS and its sustainable development capacity in China from 2008 to 2017, and corresponding suggestions are made. This study provides theoretical guidance for the sustainable development of RPSS.

(1) The information entropy model may provide a theoretical method for studying the evolution of the black box system. Based on the entropy flux and entropy production of the information entropy model, this study describes the evolution state of RPSS from the outside. The system is developing in an orderly, healthy and sustainable manner. In recent years, entropy theory has gradually expanded to the study of the evolution of various social, economic and ecological systems. For example, Li et al. used entropy flow of entropy theory to evaluate the disorder degree and developing trend of the Beijing urban ecosystem quantitatively [44]. Yang et al. confirmed that the evolution mechanism of the port city system is the negative entropy flux input from the outside and the negative entropy flow interaction within the system [45]. Song et al. used information entropy to measure the evolution of human settlements ecosystem in the lower reaches of the Yangtze River [46]. All these indicate that entropy change could explain the evolution of the system from the perspective of flow, and the model based on information entropy is a mathematical model to explain the flow-driven mechanism.

(2) Constructing the index system based on information entropy model is an important perspective of rural sustainable development research. The evaluation index system of sustainable development capacity of RPSS is constructed based on input supportive type of entropy, output pressure type of entropy, consumption metabolic type of entropy and regeneration metabolic type of entropy. The sustainable development capacity of RPSS in China has been evaluated, and the corresponding countermeasures have been analysed. However, the evaluation of sustainable development capacity is a large research topic. Mature theories and methods exist in various fields, amongst which ecological footprint [47, 48], the Index of Sustainable Economic Welfare (ISEW) [49, 50] and the Genuine Progress Indicator (GPI) [51, 52] are widely used. The foundation of rural sustainability research in China remains weak, and the systematic, complex methods are relatively limited [53]. Theoretical model construction and empirical research on rural sustainable development ability from other perspectives are important, and this study provides a perspective.

(3) The results of evolution analysis at national scale are scientific and referential. This study finds that the total entropy of RPSS in China showed a downward trend, which is consistent with the research results of $\mathrm{He}$ and Wang [54], and Wang et al [22]. It agrees with the general law of social and economic development. Thus, this study confirms that the information entropy model is suitable for mining the evolution law of RPSS at the national scale. Moreover, the previous studies of the law of system evolution based on information entropy theory were almost carried out at the scale of city, district and county [22, 42]. This study compensates for the lack in the national scale. Entropy flux of RPSS in Chongqing City and Jiangjin District has become negative since 2012 and 2013, respectively [22, 54]. However, China's entropy flux has become negative since 2014. This result provides a certain reference for judging the stage and status of the evolution of RPSS in various regions of China.

In summary, this study analyses the evolution and sustainable development capacity of RPSS in China in terms of time series, but the differences amongst regions within the country are not reflected. Judging the evolution stage, state and sustainable development level of RPSS in specific regions based on regional differences and proposing differentiated optimisation strategies are very important. Therefore, future research needs to analyse the evolution and sustainable development capacity of RPSS in time and space.

\section{Conclusions}

The analysis showed that total entropy change of RPSS in China decreased annually, including the fluctuation and decline of entropy flux and the continuous decline of entropy production from 2008 to 2017. The results showed that the carrying capacity, coordination, reductive metabolic capacity and vitality of the system were strengthened, and the system developed in an orderly direction. The sustainable development capacity score of RPSS in China showed a U-shaped trend of slowing down and then rising rapidly with 2015 as the turning point. The system's sustainable development capacity improved in general.

Through the analysis of the changes of four types of entropy indicators and their entropy weights in time series, the sustainable development of RPSS in China should be promoted from four aspects: improving the support function of the system, reducing the pressure on the system, solving the serious ecological environment problems of the system and improving the reductive metabolic capacity of the system.

\section{Acknowledgements}

This research was funded by the National Social Science Fund of China (19BGL182).

\section{References}

1. WOOD R.E. Survival of Rural America: Small Victories and Bitter Harvests. University Press of Kansas: Lawrence, America, 2008.

2. LIU Y.S., LI Y.H. Revitalize the world's countryside Nature, 548 (7667), 275, 2017.

3. LI Y.H., WU W.H., LIU Y.S. Evolution of global major disasters during past century and its enlightenments 
to human resilience building. Bulletin of Chinese Academy of Sciences, 35 (3), 345, 2020.

4. YAO Z.Y., ZHANG L.J., TANG S.H., LI X.X., HAO T.T. The basic characteristics and spatial patterns of global cultivated land change since the 1980s. Journal of Geographical Sciences, 27 (7), 771, 2017.

5. ZHOU S.Y., XU W.L. A geographical analysis on the positive investment projects in rural vitalization under time-space compression: A case study of Guangzhou City. Progress in Geography, 37 (5), 647, 2018.

6. Urban population (\% of total population) - China, The Word Bank Data. Available online: https:// data.worldbank.org/indicator/SP.URB.TOTL. IN.ZS locations $=\mathrm{CN} \&$ view $=$ chart (accessed on 18 July 2020).

7. Rural population ( $\%$ of total population) - China, The Word Bank Data. Available online: https://data.worldbank.org/ indicator/SP.RUR.TOTL.ZS?locations $=\mathrm{CN} \& \mathrm{view}=$ chart (accessed on 18 July 2020).

8. LONG H.L., QU Y. Land use transitions and land management: A mutual feedback perspective. Land Use Policy, 74, 111, 2018.

9. GAO X.Y., CHENG W.M., WANG N., LIU Q.Y., MA T., CHEN Y.J., ZHOU C.H. Spatio-temporal distribution and transformation of cropland in geomorphologic regions of China during 1990-2015. Journal of Geographical Sciences, 29 (2), 180, 2019.

10. LIU J.L., LIU Y.S., LI Y.R., HU Y.G. Coupling analysis of rural residential land and rural population in China during 2007-2015. Journal of Natural Resource, 33 (11), 1861, 2018.

11. LIU Z.M., YANG D., WEN T. Agricultural production mode transformation and production efficiency. China Agricultural Economic Review, 11 (1), 160, 2019.

12. National Bureau of statistics of the People's Republic of China. China Statistical Yearbook. China Statistical Press: Beijing, China, 2019.

13. LONG H.L. Land Use Transitions and Rural Restructuring in China. Springer Nature Singapore Pte Ltd. 2020.

14. TAN Y.Z., CHEN H., LIAN K., YU Z.N. Comprehensive evaluation of cultivated land quality at county scale: a case study of Shengzhou, Zhejiang province, China. International Journal of Environmental Research and Public Health, 17 (4), 1169, 2020.

15. LONG H.L., LIU Y.Q., HOU X.G., LI T.T., LI Y.R. Effects of land use transitions due to rapid urbanization on ecosystem services: Implications for urban planning in the new developing area of China. Habitat International, 44, 536, 2014.

16. GE D.Z., LONG H.L., ZHANG Y.N., MA L., LI T.T. Farmland transition and its influences on grain production in China. Land Use Policy, 70, 94, 2018.

17. ZHANG B.L., SUN P.L., JIANG G.H., ZHANG R.J., GAO J.B. Rural land use transition of mountainous areas and policy implications for land consolidation in China. Journal of Geographical Sciences, 29 (10), 1713, 2019.

18. LONG H.L. Land consolidation: An indispensable way of spatial restructuring in rural China. Journal of Geographical Sciences, 24 (2), 211, 2014.

19. ZHANG D.S., GAO W., LV Y.Q. The triple logic and choice strategy of rural revitalization in the 70 years since the founding of the People's Republic of China, based on the perspective of historical evolution. Agriculture, 10 (4), $125,2020$.

20. CHEN X., ZHANG T., JIA F. Industry convergence as a strategy for achieving sustainable development of agricultural complex: The case of Sandun - Lanli in China. Business Strategy and the Environment, 29 (6), 2679, 2020.

21. WANG C., LI H.Y. Conceptual and research frameworks of rural production space system. Progress in Geography, 36 (8), 913, 2017.

22. WANG C., REN M.J., Li H.Y., ZHU Y.Y. Understanding the rural production space system: A case study in Jiangjin, China. Sustainability, 11 (10), 2811, 2019.

23. ZHOU M.M., WANG C. Elements and operation mechanisms of rural production spatial system. Progress in Geography, 38 (11), 1655, 2019.

24. WANG C., ZHOU M.M., LI H.Y., HE Y.Z., MA X.S. Research on the order of rural production space system based on a system entropy model in the dissipative structure. Geographical Research, 38 (3), 619, 2019.

25. HE Y.Z., WANG C. Spatial distribution and pattern optimization of rural production space system function-A case study of Banan District, Chongqing Municipality. Economic Geography, 39 (3), 162, 2019.

26. MA X.S., WANG C. A study on the cultivation of new agricultural management entities in village based on multifunction of rural production space system. Journal of Southwest University (Natural Science Edition), 42 (4), 88, 2020.

27. WANG C., MA X.S., TANG N., LI H.Y., ZHOU M.M., HE Y.Z. Operational mechanism and restructuring of rural production space system from the perspective of farming household behavior. Progress in Geography, 37 (5), 636, 2018.

28. WANG C., LONG Z.Q. Logical cognition and mathematical expression of evolution of rural production space system. Scientia Geographica Sinica, 40 (4), 535, 2020.

29. SHANNON C.E. A mathematical theory of communication. Bell System Technical Journal, 27 (4), 379, 1948.

30. PRIGOGINE I. Time, structure, and fluctuations. Science, 201 (4358), 777, 1978

31. ZHANG Y., YANG Z.F., LI W. Analyses of urban ecosystem based on information entropy. Ecological Modelling, 197 (1-2), 1, 2006.

32. GLANSDORFF P., PRIGOGINE I. Strongly nonequilibrium states. (Book reviews: Thermodynamic Theory of Structure, Stability and Fluctuations). Science, 176 (4042), 1410, 1972.

33. SHEN X.F., HU G., JIANG L. Dissipative Structure Theory. Shanghai People's Publishing House: Shanghai, China, 1987.

34. MARTIN M.A, TAGUAS F.J. Fractal modeling, characterization and simulation of particle size distribution in soil. Proceedings of the Royal Society A, 454 (1973), 1457,1998

35. ALFONSO L., HE L., LOBBRECHT A., PRICE R. Information theory applied to evaluate the discharge monitoring network of the Magdalena River. Journal of Hydroinformatics, 15 (1), 211, 2013.

36. ANTROP M. Landscape change: Plan or chaos?. Landscape and Urban Planning, 41 (3-4), 155, 1998.

37. HERRMANN-PILLATH C., KIRCHERT D., PAN J. Disparities in Chinese economic development: Approaches on different levels of aggregation. Economic Systems, 26 (1), 31, 2002.

38. GUO R.Z., SHEN H.J., YANG M.H. Spatial-temporal assessment and evolution research of information entropy of land use structures in Chang-Zhu-Tan Region. Chinese 
Journal of Agricultural Resources and Regional Planning, 40 (9), 92, 2019.

39. WANG X.J., CHEN Y., QI P., ZHANG R.Z. Dynamic evolution and prediction of land use structure in Zhangye. Journal of Arid Land Resources and Environment, 26 (4), 86, 2012.

40. FENG J. Modeling the spatial distribution of urban population density and its evolution in Hangzhou. Geographical Research, (5), 635, 2002.

41. DI Q.B., HAN Y.X. Sustainable Development Ability of China's Marine Ecosystems in the Perspective of Entropy. Scientia Geographica Sinica, 34 (6), 664, 2014.

42. LIN Z.M., XIA B. Sustainability analysis of the urban ecosystem in Guangzhou City based on information entropy between 2004 and 2010. Journal of Geographical Sciences, 23 (3), 417, 2013.

43. LIANG L.T., QIN M.Z. Study on agricultural non-point source pollution in China. China Social Sciences Press: Beijing, China, 2013.

44. LI J.X., YANG L., YANG L., ZHANG C., HUO Z.M., CHEN M.H., LUAN X.F. Quantitative assessment of urban ecosystem services flow based on entropy theory: A case study of Beijing, Chinese Journal of Applied Ecology, 29 (3), 987, 2018

45. YANG S., PAN J., JI Z.M. The evolution mechanisms and law of Lianyungang port-city system based on principles of dissipative structure. Scientia Geographica Sinica, 31 (7), 781, 2011.

46. SONG F., YANG X.H., WU F.F., LIU T. Evaluation of evolution and development of the human habitat ecosystem in the lower Yangtze region based on information entropy. Research of Soil and Water Conservation, 26 (1), 245, 2019.
47. UDEMBA E.N. A sustainable study of economic growth and development amidst ecological footprint: New insight from Nigerian Perspective. Science of the Total Environment, 732, 139270, 2020.

48. AKADIRI S.S., ALOLA A.A., ALOLA U.V., NWAMBE C.S. The role of ecological footprint and the changes in degree days on environmental sustainability in the USA. Environmental Science and Pollution Research, 27 (20), 1, 2020.

49. MENEGAKI A.N., TUGCU C.T. Two versions of the Index of Sustainable Economic Welfare (ISEW) in the energy-growth nexus for selected Asian countries. Sustainable Production and Consumption, 14, 21, 2018.

50. O'MAHONY T., ESCARDÓ-SERRA P., DUFOUR J. Revisiting ISEW valuation approaches: the case of Spain including the costs of energy depletion and of climate change. Ecological Economics, 144, 292, 2018.

51. TALBERTH J., COBB C., SLATTERY N. The genuine progress indicator 2006: A tool for sustainable development. Redefining Progress, 510, 1, 2007.

52. HASHIM M., MOHAMAD A., SIFAT I.M. The sustainable development consequences of IMF debt vs. capital control: Comparing progress in GPI and GDP terms for Korea and Malaysia. Journal of Cleaner Producion, 234, 725, 2019

53. HE Y.H., WU J.G., ZHOU G.H., ZHOU B.B. Discussion on rural sustainability and rural sustainability science. Acta Geographica Sinica, 75 (4), 736, 2020.

54. HE Y.Z., WANG C. The evolution and sustainable development capacity of rural production space system based on information entropy. Journal of Natural Resources, 34 (4), 815, 2019. 